\title{
Development of a Forceps Force Limiter Using Leaf Spring Buckling
}

\section{CURRENT STATUS: POSTED}

Research Square

\section{Satsuya Noda}

Department of Mechanical System Engineering, National Institute of Technology, Fukushima College, 30 Tairakamiarakawa-aza-Nagao, Iwaki, 970-8034 Fukushima, Japan

snoda@fukushima-nct.ac.jpCorresponding Author

\section{DOI:}

$10.21203 / \mathrm{rs} .2 .22608 / \mathrm{v} 1$

\section{SUBJECT AREAS}

Robotics

KEYWORDS

Buckling, Forceps, Force limiter 
Abstract

To prevent accidents in minimally invasive surgeries, force limiters have been developed for forceps grippers. When a force limiter is in use, if the absolute value of its spring constant is reduced, the risk of damage to the organs decreases. This paper proposes the use of a leaf spring buckling mechanism as a force limiter for forceps. The results obtained indicate that the spring constant of a buckled leaf spring is lower than that of a normal coil spring. Furthermore, the use of a leaf spring allows the independent adjustment of its thickness and width, based on the stress and force values. This enables an easy calibration of the threshold value. In the experiments, the spring constant of the buckled leaf spring was $0.15 \mathrm{~N} / \mathrm{mm}$, which is half of that of a normal coil spring. After calibrating the gripping force, it was confirmed that the force limiter reduced the extent of damage to the dummy organs in the ex vivo experiments.

\section{Full Text}

Due to technical limitations, full-text HTML conversion of this manuscript could not be completed. However, the manuscript can be downloaded and accessed as a PDF or as a LaTeX file in the Supplementary Files section.

Figures 


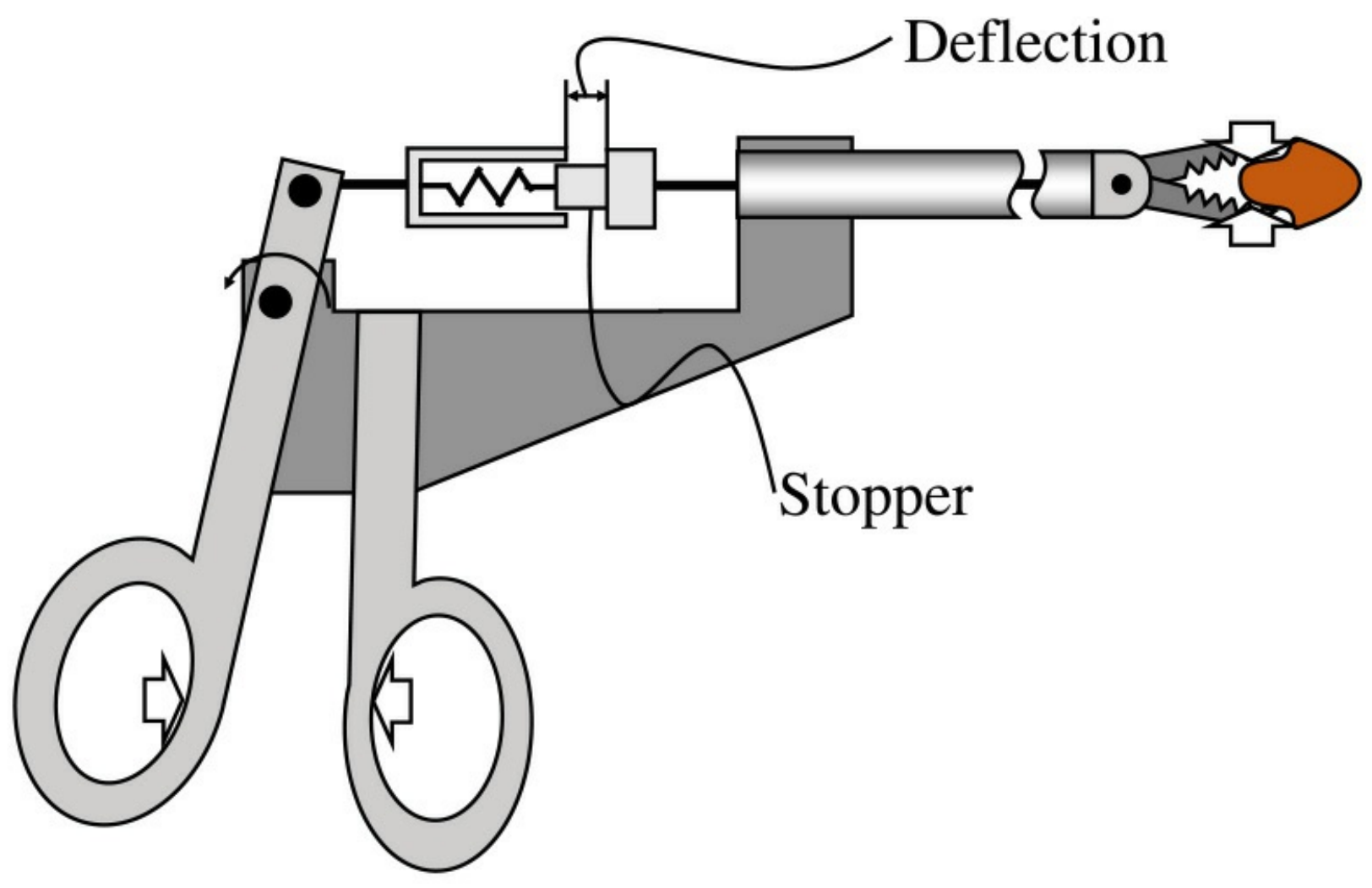

Figure 1

General force limiter mechanism. 

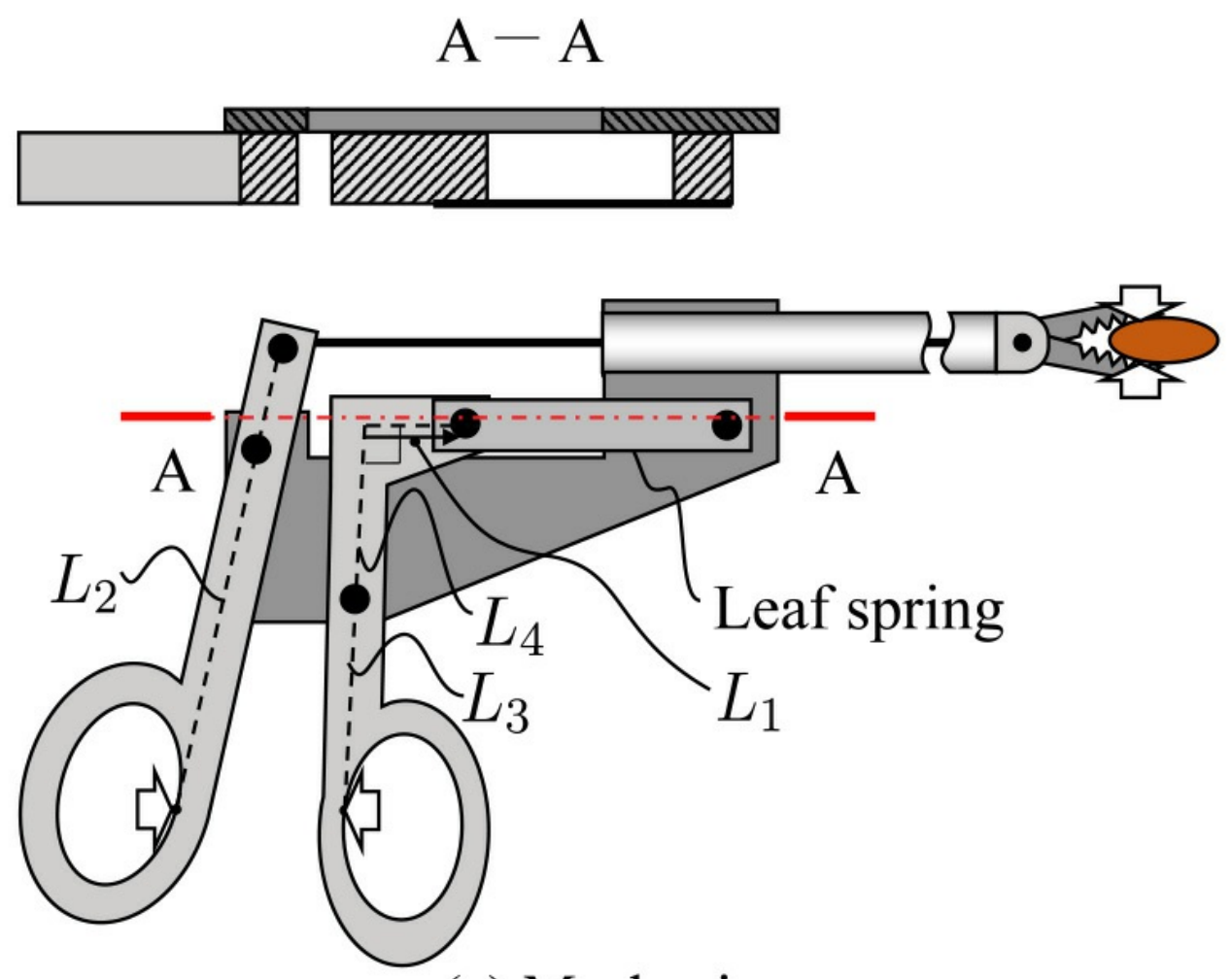

(a) Mechanisms.

Section A-A
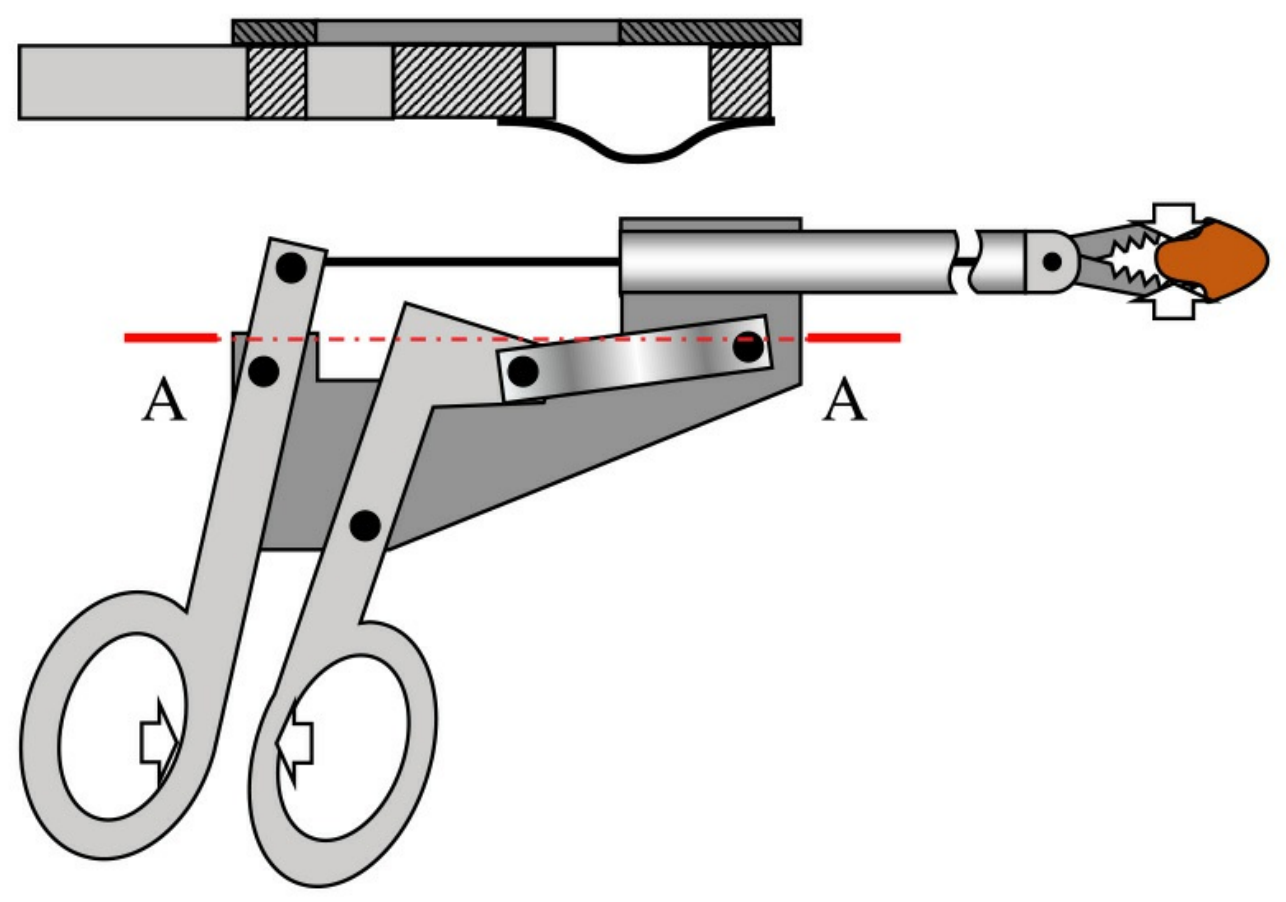

(b) Force limiter in operation.

Figure 2

(a) Mechanisms. (b) Force limiter in operation. Proposed forceps gripper. 


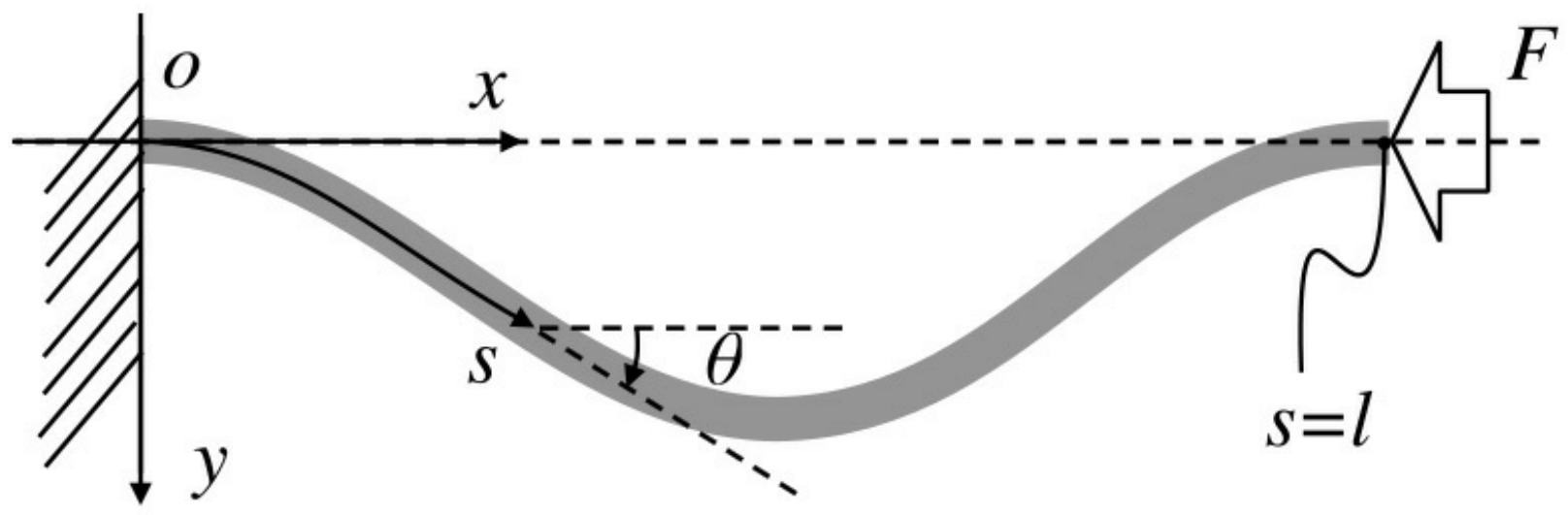

Figure 3

Coordinate system of the buckled leaf spring.

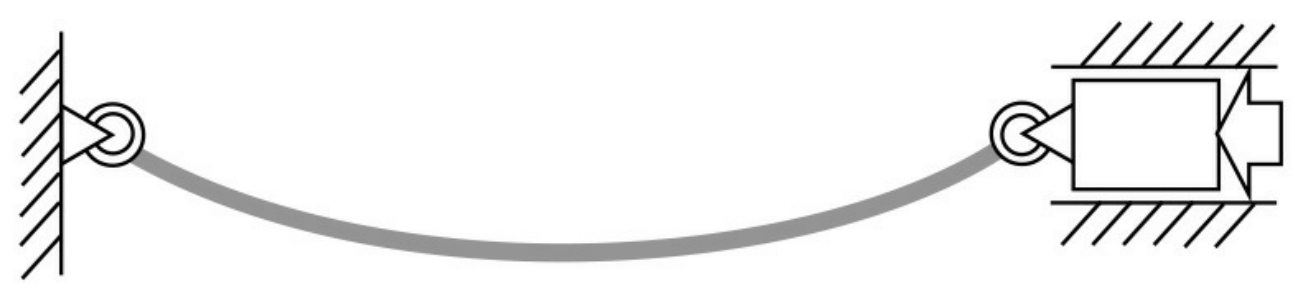

(A) Moment zero

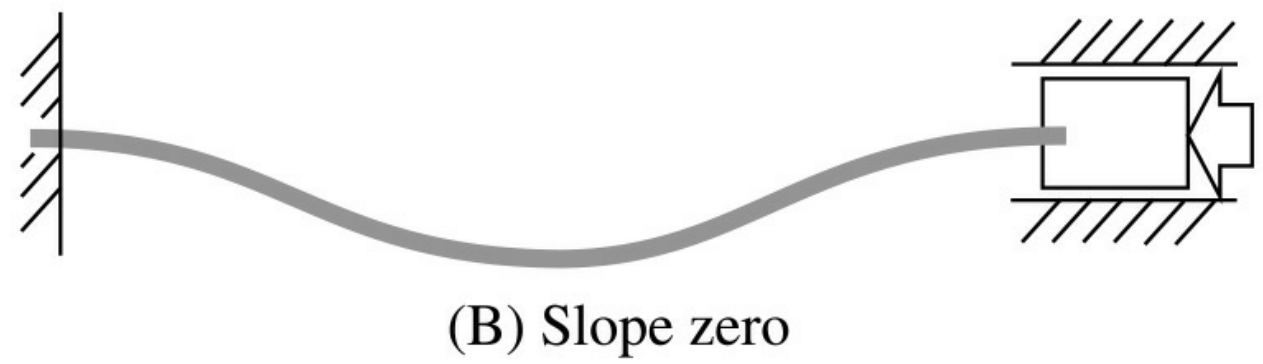

Figure 4

Fixation model of the leaf spring at the edge. 


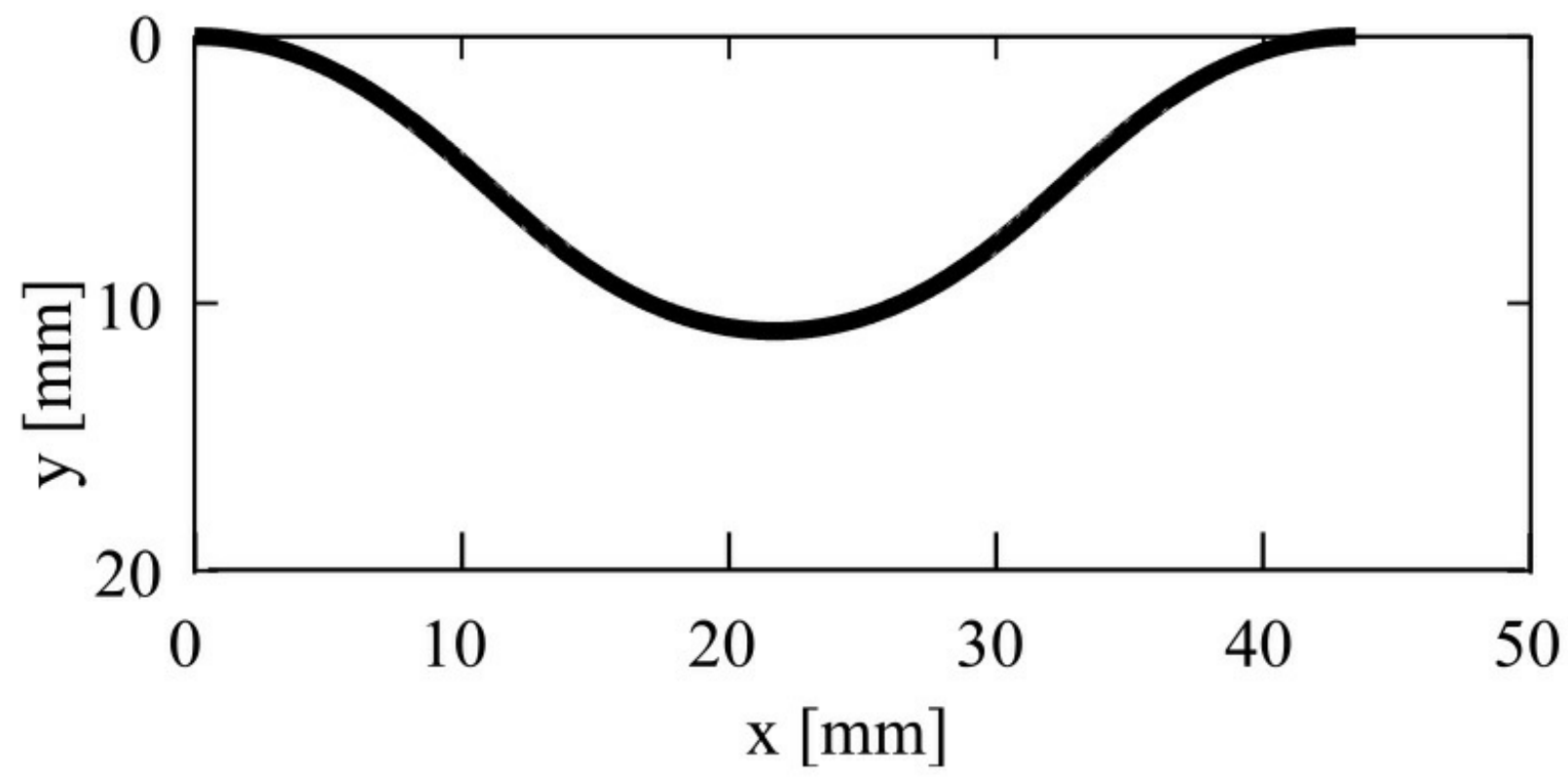

Figure 5

Deformed shape of buckled leaf spring in simulation with I_ $\{\mathrm{ij}\}=50 \mathrm{~mm}$ and Delta $\mathrm{x}_{-} \mathrm{i}=6.5$ $\mathrm{mm}$.

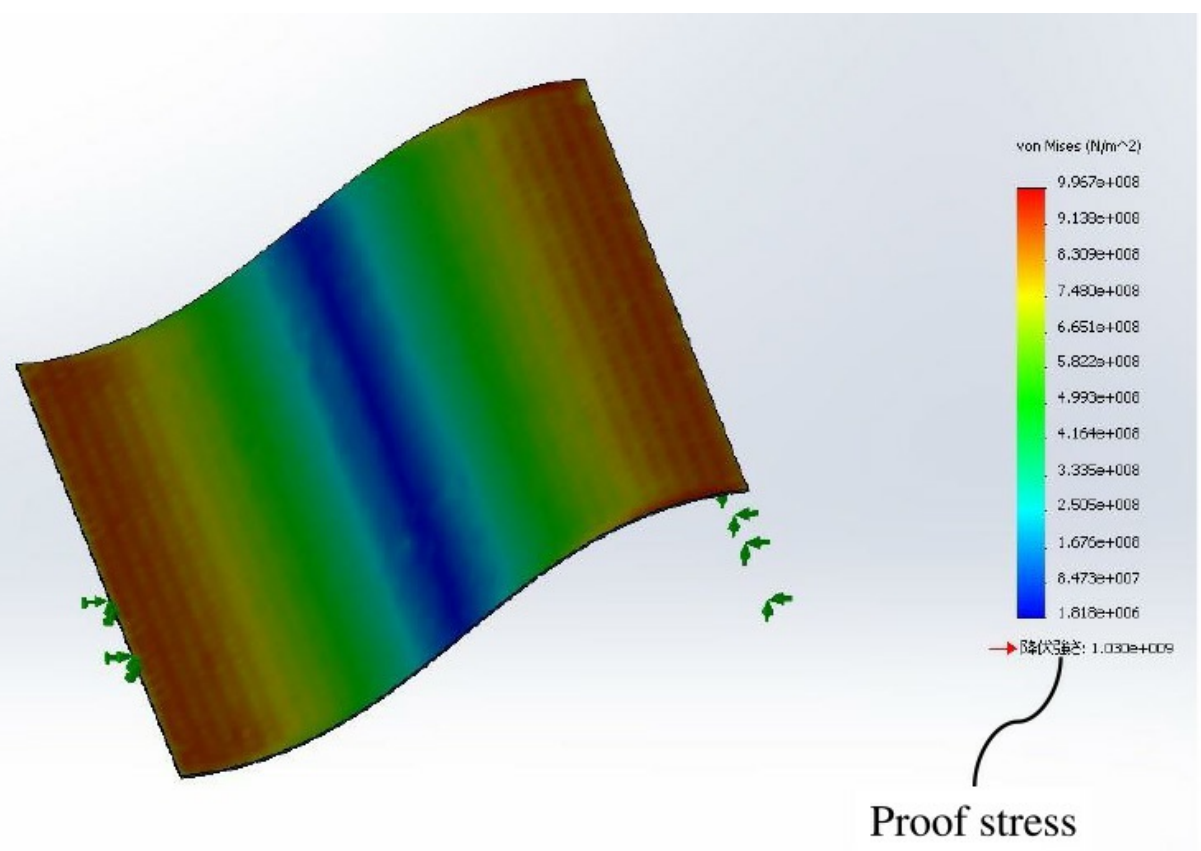

Figure 6

FEM result of the stress test. 


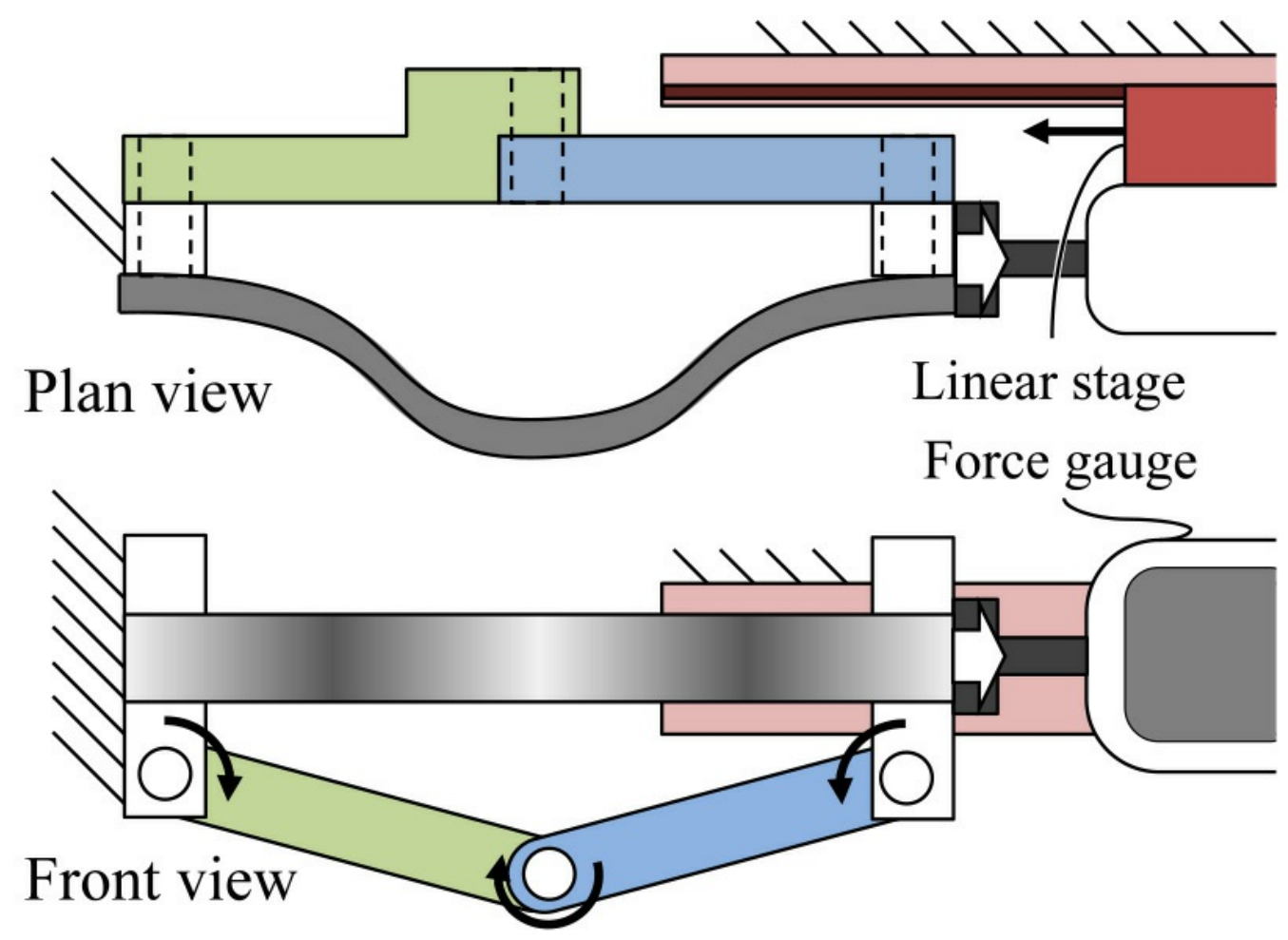

Figure 7

Experimental setup for force measurement. 


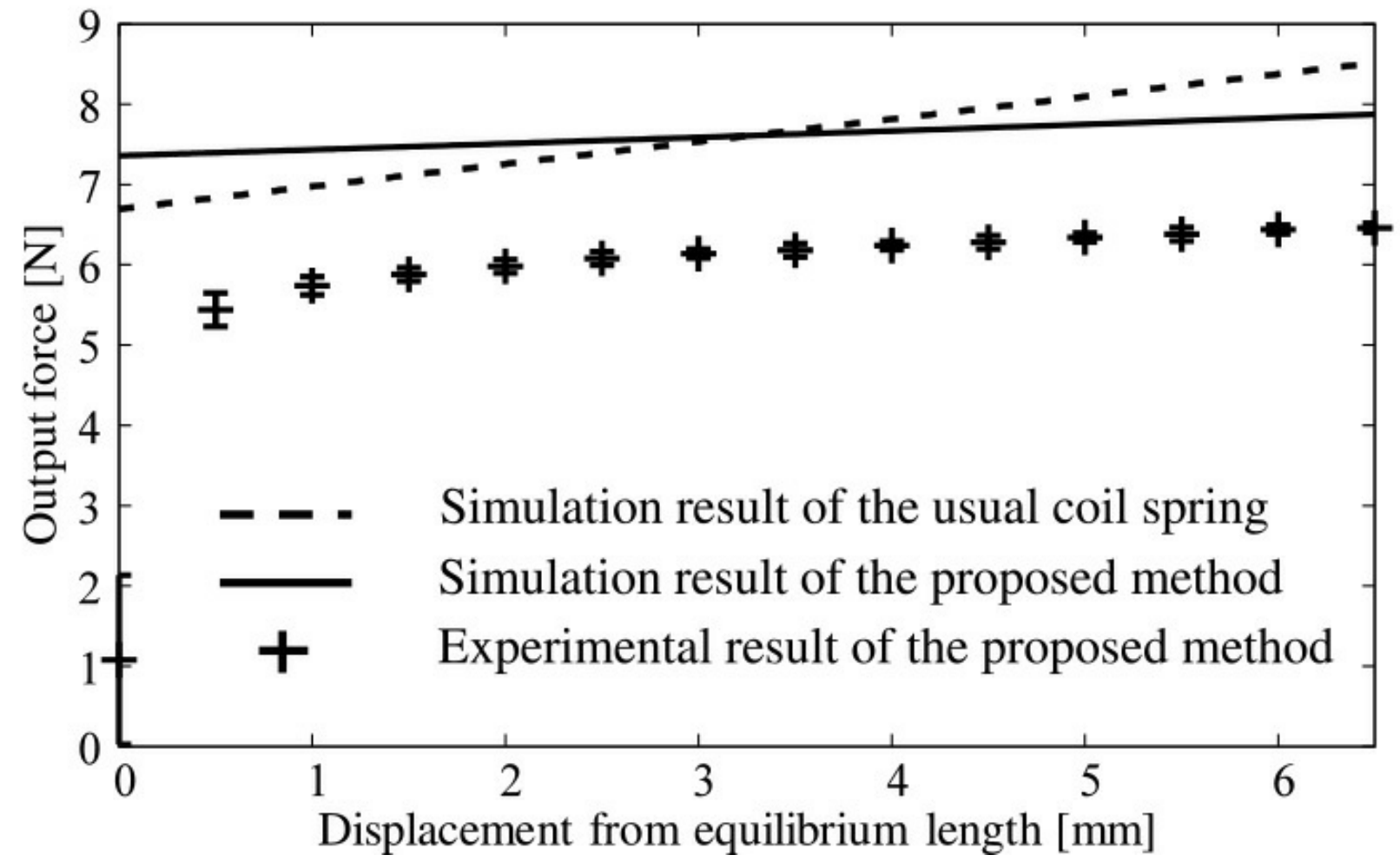

Figure 8

Simulation and experimental result of buckling force with respect to displacement. Error bars show the standard deviation. 

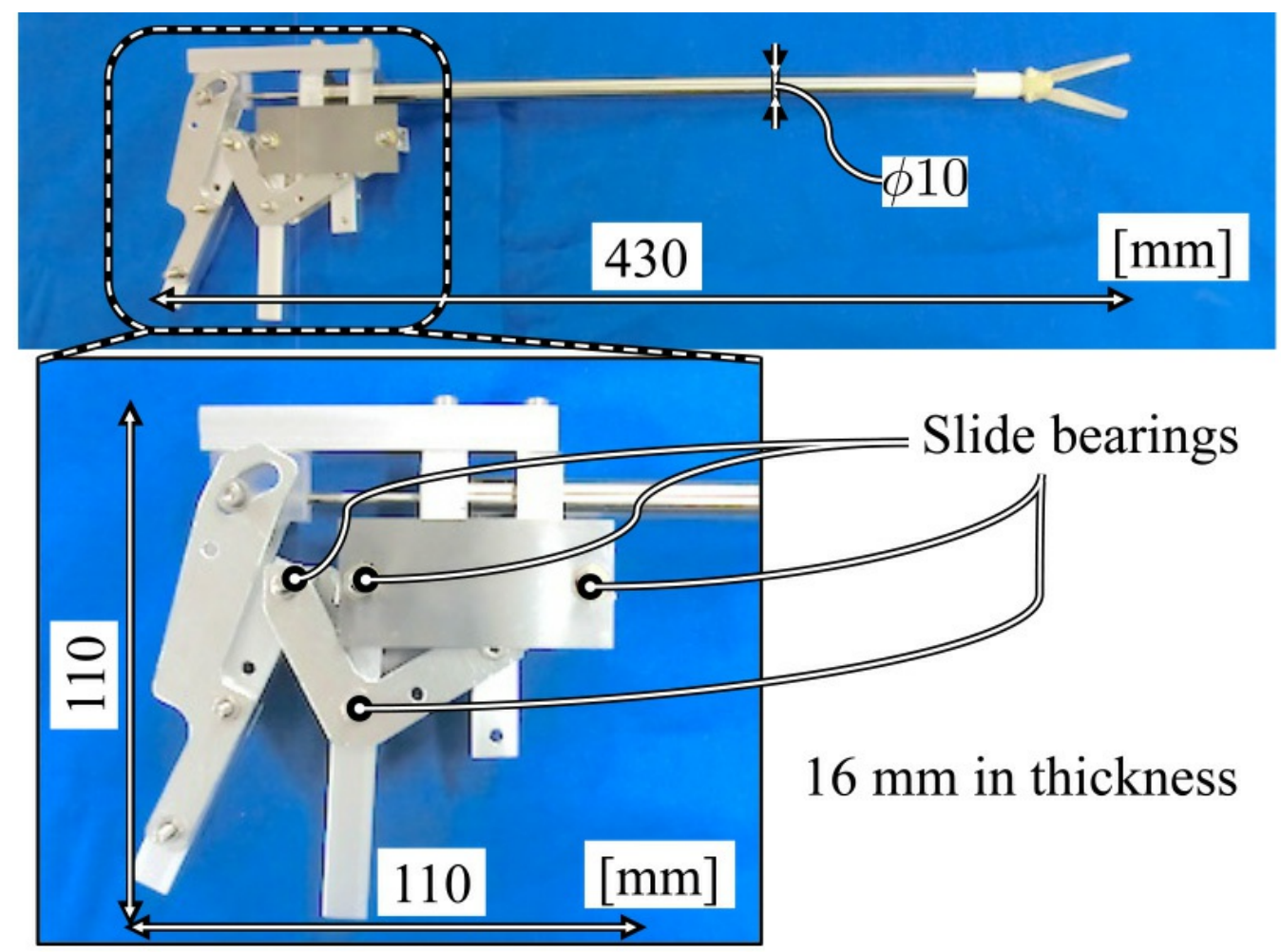

Figure 9

Prototype force limiter.

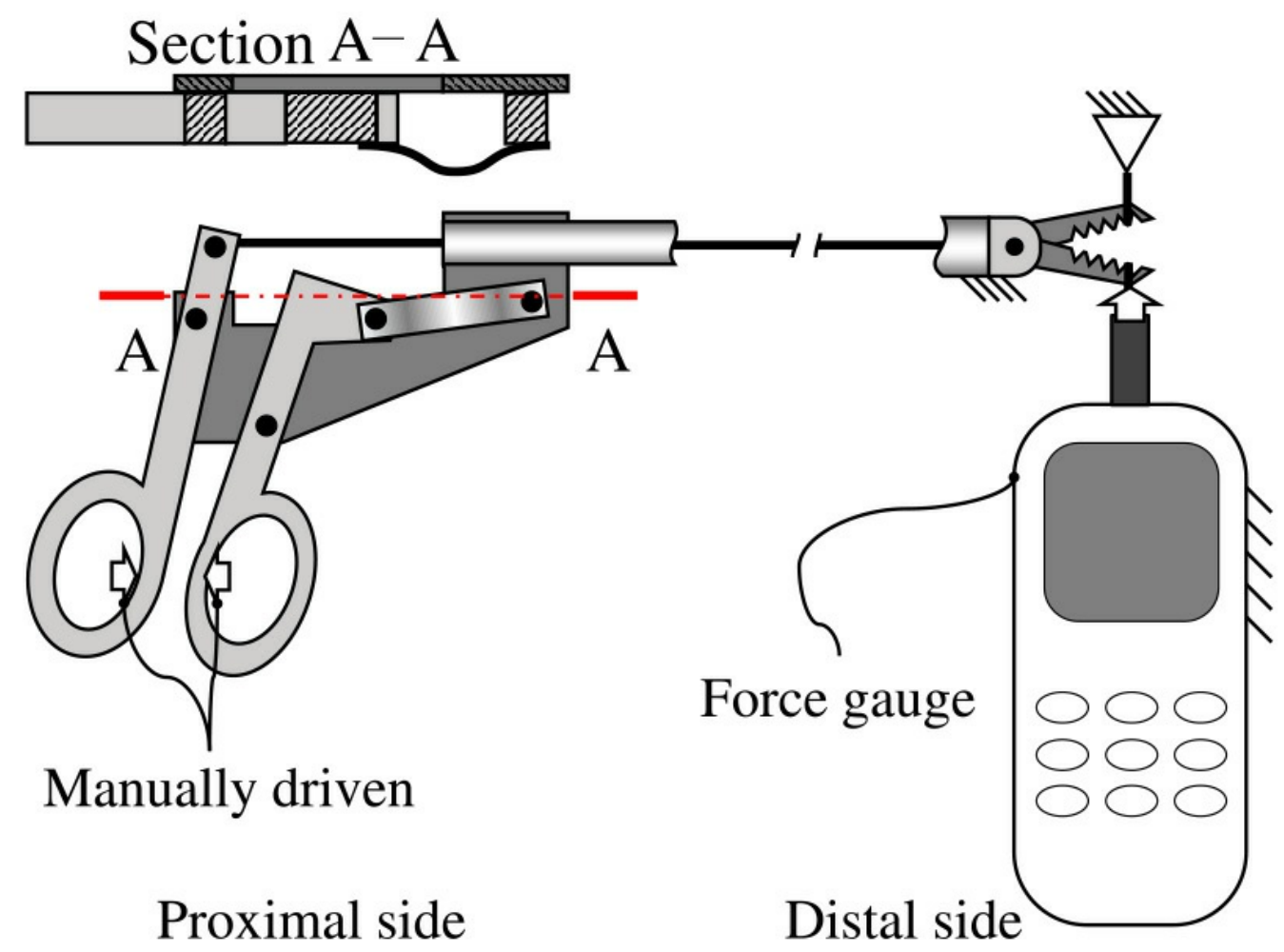

Figure 10

Experimental setup for gripping force measurement. 


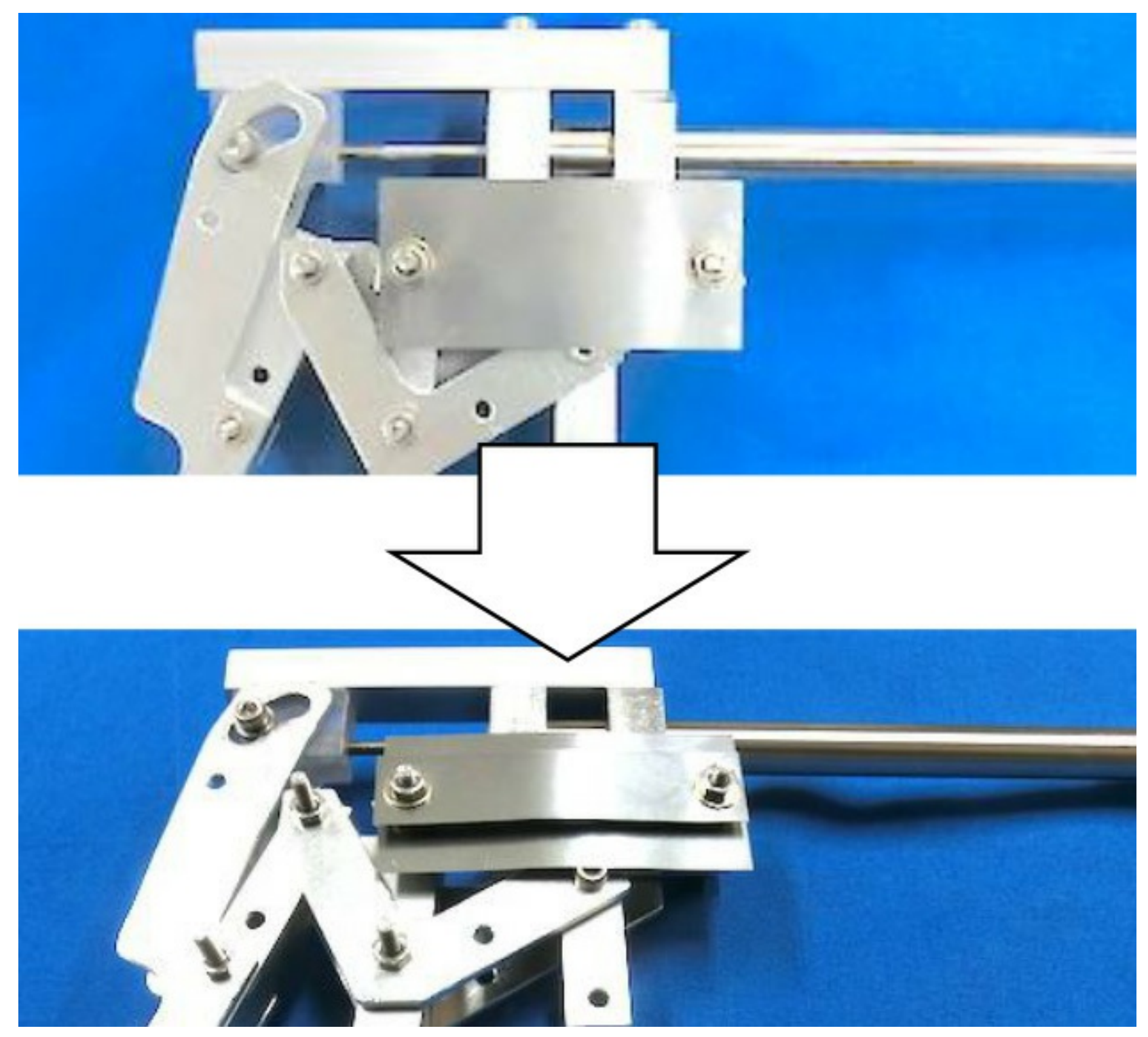

Figure 11

Installation of additional leaf spring. 


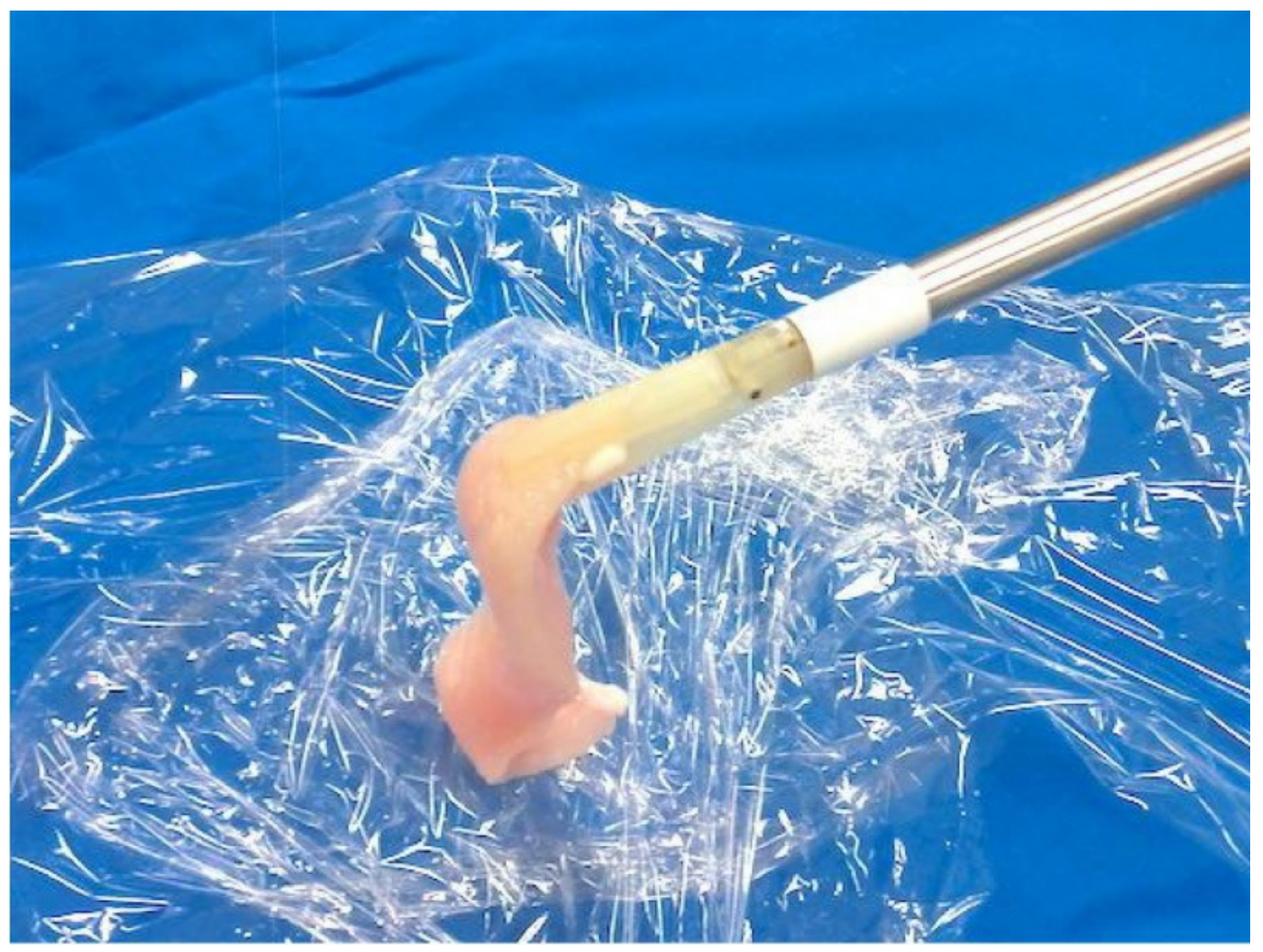

Figure 12

Ex vivo experiments of the force limiter. 


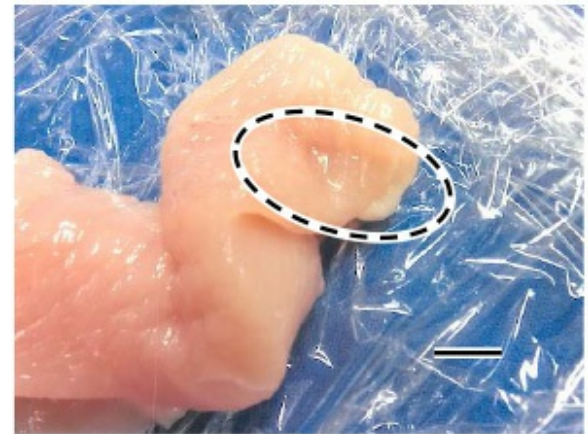

(A)

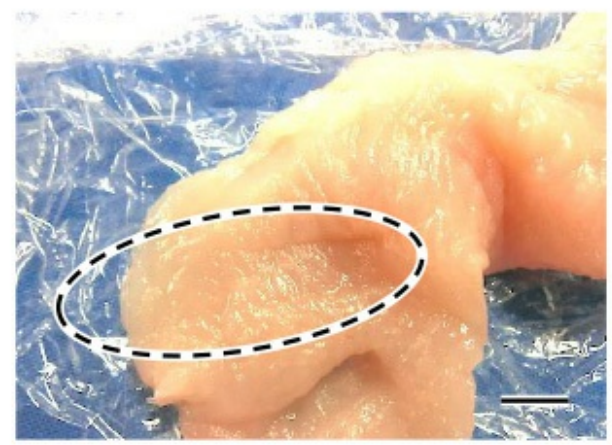

(C)

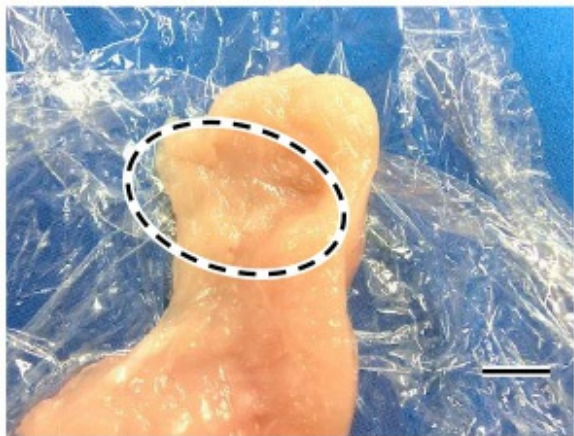

(B)

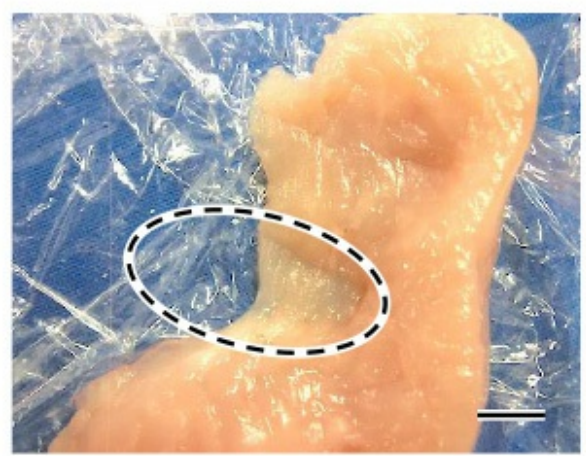

(D)

Figure 13

Chicken breast after ex vivo experiments.\} Dashed lines show the gripped part and each bar represents 10 mm. (A) Force limiter. (B) $7.4 \mathrm{~N}$ (C) $11.4 \mathrm{~N}$ (D) $20.0 \mathrm{~N}$. 


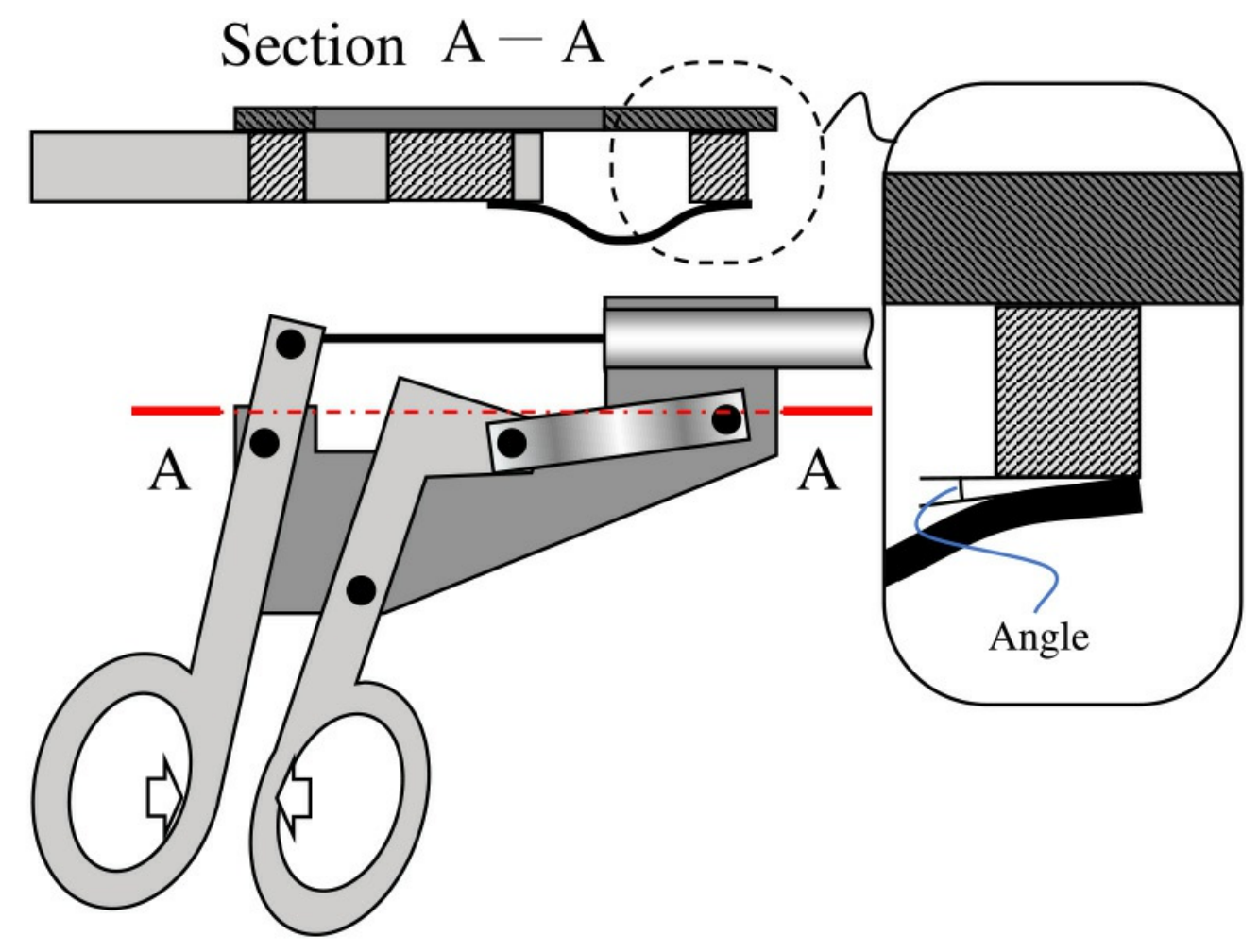

Figure 14

Edge of the leaf spring. 


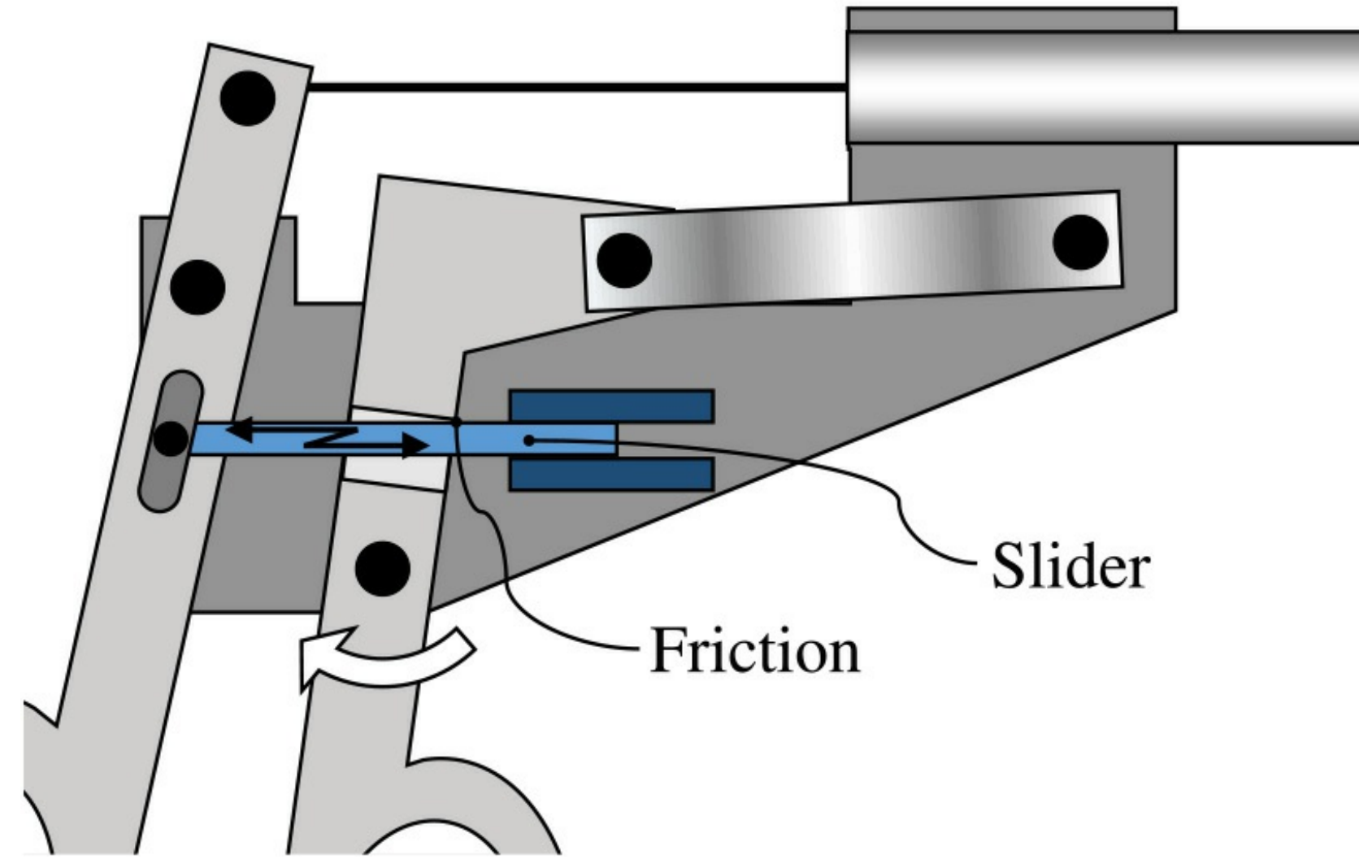

Figure 15

Proposed locking mechanisms.

\section{Supplementary Files}

This is a list of supplementary files associated with this preprint. Click to download. bmc_article_rev01.tex 